\title{
Cardiac Arrest Requiring Cardiopulmonary Resuscitation
}

National Cancer Institute

\section{Source}

National Cancer Institute. Cardiac Arrest Requiring Cardiopulmonary Resuscitation. NCI

Thesaurus. Code C141268.

Cardiac arrest that is treated by CPR and/or defibrillation, regardless of outcome. 